\title{
Zihniyet Kuramı ve Öğrenme Motivasyonu
}

\section{Samih BAYRAKÇEKEN* ${ }^{*}$ Osman SAMANCI ${ }^{* *}$ Hakime Nur GÖKBULUT ${ }^{* * *}$}

\section{Makale Bilgisi \\ ÖZET}

Makalenin Türü: Derleme Makale Makalenin Geliș Tarihi: 23.8.2021

Makalenin Kabul Tarihi: 02.12.2021

DOI: $10.54971 /$ synergy. 986217
Zor problemlerle karşılaştıklarında, bazı öğrenciler hemen pes edip çalışmayı bırakırken, bazıları problemi çözmek için neden daha fazla uğrașmaktadırlar? Çocukların bașarısızlıkla nasıl bașetmeye çalıștıkları üzerine araștırmalar yapan Amerikalı Sosyal Psikolog Carol Dweck, bu durumu zihniyet kuramı ile açıklamaktadır. Öz inanç veya örtük zekâ kuramı adı ile de ifade edilen bu kurama göre, insanların temel özellikleri ile ilgili inançları; onların motivasyonlarını, öğrenmeye yaklaşımlarını ve bașarı durumlarını yakından etkilemektedir. Bu kurama göre insanlar, 'sabit zihniyet' ve 'gelişme zihniyetine' sahip olmak üzere iki gruba ayrılmaktadırlar. Sabit zihniyete sahip bireyler, zekâ, yetenek veya kişilik gibi temel özelliklerinin değişmeyeceğine inanırlar. $\mathrm{Bu}$ zihniyete sahip bireylerin gelișme umutları fazla olmadığından genellikle öğrenmeye karșı motivasyonları, azim ve kararlılıkları da düşüktür. Gelișme zihniyetine sahip bireylerde; zekâ, yetenek gibi temel özelliklerinin değiştirilebileceği düşüncesi hakimdir. Gelişme zihniyetine sahip bireyler öğrenmeye karșı yüksek bir motivasyona sahip olup, daha iyi olmak için sürekli çaba sarfederler. Yapılan çalışmalar zihniyetin değiştirilebileceğine, gelişme zihniyetinin okuldaki yüksek bașarı ile bağlantılı olduğuna dair önemli kanıtlar olduğunu ortaya koymaktadır. Bu çalıșma, gelișme zihniyetinin öğrenme motivasyonu üzerine etkisini, ilgili literatüre göre incelemeyi amaçlamaktadır. Zihniyet kuramı, öğrenmenin anlaşılması ve artırılması için geniş bir çerçeve sunmaktadır. Bu nedenle çalıșmanın, eğitimciler, ebeveynler ve öğrenciler için uygun öğrenme ortamları sağlamada yararlı olacağı düşünülmektedir.

Anahtar Kelimeler: Zihniyet Kuramı, Öğrenme Motivasyonu, Sabit Zihniyet, Gelişme Zihniyeti.

\footnotetext{
${ }^{*}$ Prof. Dr., Atatürk Üniversitesi Kazım Karabekir Eğitim Fakültesi Matematik ve Fen Bilimleri Eğitimi Bölümü, Erzurum (eposta: samih@atauni.edu.tr) ORCID ID. https://orcid.org/0000-0001-8777-6714 **Prof. Dr., Atatürk Üniversitesi Kazım Karabekir Eğitim Fakültesi Temel Eğitim Bölümü, Erzurum (eposta: osamanci@atauni.edu.tr) ORCID ID. https://orcid.org/0000-0003-3620-7604 ${ }^{* * *}$ Prof.Dr.,Gazi Üniversitesi Gazi Eğitim Fakültesi Güzel Sanatlar Eğitimi Bölümü, Ankara (eposta:nurgokbulut2@gmail.com) ORCID ID. https://orcid.org/0000-0002- 2561-969X
} 


\title{
Theory of Mindset and Motivation to Learn
}

\begin{abstract}
Why do a number of students struggle more while others easily give up studying when encountering tough problems? American Social Psychologist Carol Dweck, who does research on how children attempt to cope with failure, explains this case through the theory of mindset. According to this theory, which is also referred to as Implicit Beliefs about Intelligence or Implicit Theory of Intelligence, people's beliefs about their own basic skills influence their motivations, approaches to learning and achievement levels vastly. This theory views that people are divided into two groups: ones with a fixed mindset and others with a growth mindset. Individuals with a fixed mindset believe that their basic features such as intelligence, abilities and personalities do not change. Individuals with such a mindset generally have low motivation, enthusiasm and decisiveness as they do not have high hopes to improve. For the individuals with growth mindset, the prevailing opinion is that basic traits like intelligence and aptitude may be changed. Individuals with growth mindset have high motivation to learn and always struggle to succeed. Studies conducted provide significant proofs that mindset may be modified and growth mindset is closely related to high achievement at school. This study aims to investigate the impact of growth mindset on learning motivation regarding the relevant literature. Theory of mindset presents a wide framework to understand and improve learning. Therefore, it is believed that the present study will be beneficial for educators, parents and students in providing appropriate learning environments.
\end{abstract}

Keywords: Theory of Mindset, Motivation to Learn, Fixed Mindset, Growth Mindset.

\section{Gíriş}

Öğrencilerin akademik başarı yönünden birbirlerinden farklı olmalarının nedenleri; zihinsel yetenek, çevre, öğretmen ve okul niteliği gibi birçok faktörle ilişkilendirilmektedir. Ancak bu faktörlerin her öğrencide eşit olduğu düşünüldügünde bile, öğrencilerin performanslarının birbirlerinden çok farklılaştığı bilinmektedir. Öğrencilerdeki performans farklılıklarının açıklaması için araştırmacılar çoğunlukla motivasyon kavramı üzerinde durmaktadırlar (LinSiegler, Dweck and Cohen, 2016).

Çok sayıda farklı tanımlarına rastlanmakla birlikte Bedford (2017) motivasyonu; belli amaçlara ulaşmaları için öğrencilerin davranışını uyaran, yönlendiren ve sürdüren içsel bir durum olarak tanımlamaktadır. Shunk ve diğerlerine (2008)'e göre ise motivasyon; amaca yönelik etkinliklerle ateşlenen, yönlendirilen ve sürdürülen bir süreci ifade eder. Motivasyon; bireylerin hedeflerine ulaşmak, ihtiyaçlarını karşılamak ve bir değeri sürdürmek için çabalarını sağlayan itici güçtür.

Motivasyon tanımlarında, ihtiyaçlar, değerler ve amaçlar ön plana çıkan temel unsurlardır. Motivasyon tanımlarında ön plana çıkan bu temel unsurlardan birincisi ihtiyaçlardır. İhtiyaçlar; yemek, uyku ve su gibi yaşamsal türden olup fizyolojik veya birincil ihtiyaçlar olarak nitelendirilebilir. Bu ihtiyaçlar doğası gereği biyolojiktir ve nispeten sabittir. Davranış üzerindeki etkileri genellikle açıtır ve bu nedenle tanımlanması daha kolaydır. Bu ihtiyaçlar kültüre ve kişiye göre önemli ölçüde değişiklik gösterebilir.

Motivasyon tanımlarında ikinci önemli unsur değerlerdir. Değerler; öğrenme motivasyonu açısından önemli görülen temel unsurlardan birisidir. Öğrenciler öğrenme etkinliklerini değerli görmedikçe, hedeflerine ulaşmak için yeterince uzun süre bir göreve katılamazlar ya da öğrenmeyi sürdüremezler.

Motivasyon tanımlarında ön plana çıkan bir diğer unsur ise amaçlardır. Amaçlar; öğrencilerin ulaşmayı arzu ettikleri sonuçlardır. Amaçlar veya hedefler, öğrenme için önemlidir. Amaçlar, çaba 
sarf edip etmeme, dikkatin yönlendirilmesi, planlama ve öğrenme gibi tutum ve davranışlara rehberlik ederler (Hastings ve West, 2011; Mullins and Christy, 2011).

Arnold, Robertson ve Cooper (1991)'a göre, motivasyon sürecinin üç temel bileşeni bulunmaktadır: Bunlar; yön, yoğunluk ve kararlılıktır. Yön; bireyin ilk belirlemesi gereken bileșen olup amaç ya da hedef anlamında kullanılmaktadır. Yoğunluk; bir işi başarmak için sarfedilen çabanın ya da enerjinin yoğunluğudur. Kararlılık veya sebat ise, pes etmeden gayretini sürdürmek veya güçlü bir bağlılıkla çalışma yoğunluğunu düşürmeden hedefe varmaya çalışmaktır. Bir öğrencinin öğrenmesi için motivasyona olan ihtiyacı, bir otomobilin hareket için enerjiye olan ihtiyacına benzetilebilir. Otomobil ne kadar ileri teknolojiye sahip olursa olsun enerjisiz hareket ettirilemez. Öğretmenler veya ebeveynler tarafından öğretme-öğrenme süreçlerinde motivasyon stratejilerinin uygulanması öğrencilerin öğrenme ve başarılarının artırılması için son derece önemlidir (Dweck ve Cohen, 2016; Lin-Siegler,2016; Şahin, 2007)

Motivasyon sürecinin daha iyi anlaşılması ve öğrencilerin motivasyonlarının iyileștirilmesi için birçok motivasyon kuramı geliştirilmiştir. Her yaştan bütün bireylerin okulda veya okul dişında yaşam boyu öğrenmeleri için daha yüksek bir motivasyona ihtiyaç duydukları kabul edilmektedir (Bayrakçeken, Oktay, Samancl, ve Canpolat, 2021; Deckers, 2018; Öztürk, 2012; Pakdel, 2013;). Motive olan öğrencilerin göreve katılım, çalışmaya daha uzun süre devam etme, daha iyi öğrenme ve standart başarı testlerinde daha iyi performans gösterme gibi avantajlar elde ettikleri bilinmektedir (Pintrich, 2003).

Motivasyon, bir üründen daha çok bir süreçtir. Motivasyon, fiziksel veya zihinsel faaliyetler olarak kendini gösterir. Fiziksel etkinlikler çaba, sebat ve diğer açık eylemleri gerektirir. Zihinsel etkinlikler planlama, prova, düzenleme, izleme, karar verme, çözme gibi zihinsel eylemleri içerir. Motivasyonun ölçülmesi de uygulayıcılar ve araştırmacılar için büyük önem arz etmektedir. Bu amaçla motivasyonun göstergesi olarak kabul edilen; görev seçimi, çaba, sebat ve başarı gibi unsurlar, doğrudan gözlem, bireylerin kendileri ile ilgili değerlendirmeleri, anketler, mülakatlar ve başkalarının değerlendirmeleri gibi tekniklerle ölçülmeye çalışılır (Schunk, Pintrich ve Meece, 2014).

Motivasyonla ilgili ön plana çıkan konulardan birisi de bireylerin öğrenmeye nasıl motive olduklarıdır. Öğrenme motivasyonu üzerine yapılan çalışmalar bu konuda önemli bilgiler sunmaktadır. Konu ile ilgili yapılan araştırmalarda dikkate alınması gereken bazı temel bilgiler şunlardır (Council, 2000; NASEM, 2018):

- Bireylerin öğrenme ve kendilerini geliştirme süreçleri daha çok içsel nedenlere dayanmaktadır.

- Bireyler başedebilecekleri bir zorlukla karşılaştıktan sonra öğrendiklerinde daha iyi motive olmaktadırlar.

- Kendi performansını değerlendirmekten çok, öğrenmeye odaklanan bireyler daha kolay motive olabilirler.

- Kendi yetkinliklerini geliştirmeyi önemseyen bireyler öğrenmeye yönelik yeni hedefler belirleyebilirler.

- Eğitimciler, öğrencilerin performanslarını belirlemekten çok onların öğrenmeye odaklanmalarını sağlamak için rehberlik etmelidirler.

Dweck ve arkadaşları (2006) tarafından uzun yıllar çalışılan motivasyon konularından elde edilen bilgiler, bireylerin kendileri ile ilgili bilinçli veya bilinçsiz olarak taşıdıkları inançların; onların başta öğrenme motivasyonları olmak üzere hayatlarının hemen her yönü üzerinde çok önemli etkisi olduğunu göstermektedir. Bu inançlar; zihniyetler, örtük kuramlar veya öz-teoriler şeklinde değişik isimlerle de ifade edilmektedir (Bernecker ve Job, 2019). Bu inançların kuram olarak 
nitelendirmesinin nedeni, şeklen de olsa bilimsel kuramlara benzer bir işleve sahip olmasından kaynaklanmaktadır (Çelik ve Bayrakçeken, 2006 ). Bu çalışmada gelişme ve sabit zihniyet ile ilgili bir literatür taraması yapılarak öğretmen, yönetici ve ebeveynlerin dikkatlerine sunulması amaçlanmaktadır.

\section{Sabit ve Gelişme Zihniyetinin Öğrenci Motivasyonuna Etkisi}

Bazı öğrenciler, zihinsel yeteneklerinin sabit olduğunu düşünerek, zekânın değişmeyen bir nitelik olduğuna inanırlar. Bu öğrenciler, kendilerinin ne kadar akıllı oldukları ile fazla ilgilenerek çoğunlukla zekâlarını ispatlayacak görev ve sorumluluklar almaya çalışır, zekâlarını zorlayacak görev ve sorumluluklardan kaçınırlar. Bunun aksine bazı öğrenciler ise zihinsel yeteneğin çaba ve eğitimle gelişebileceğine inanırlar. Bu düşünceye sahip öğrenciler başarı için emek ve çabanın gerekli olduğunu düşünürler. Zekâlarını geliştirebileceklerine inanan öğrenciler, kendilerini geliştirmeye yönelik tüm aktivitelere gönüllü olarak katılır, çevreye karşı daha akıllı görünmek gibi bir kaygı taşımazlar (Dweck, 2007).

Psikoloji ve nöroloji alanındaki birçok araştırma, gelişme zihniyetini desteklemektedir. Beynin zamanla plastisitesinin arttığı, öğrenmenin insan zekâsı üzerinde önemli düzeyde gelişime neden olduğu, bireyin engellerle yüz yüze gelip çaba ve sebat gösterdiğinde zihinsel olarak çok önemli gelişim kaydettiği konusunda hemfikirdir (Au, Sheehan, Tsai, Duncan, Buschkuehl ve Jaeggi, 2015; Dweck, 2007; Jaeggi, Buschkuehl, Jonides ve Perrig, 2008). Gelişme zihniyeti; bireyin zekâsının ve kişilik özelliklerinin zamanla değişip büyüyebileceğine olan inanç şeklinde tanımlanmakta ve uygun stratejilerle, bireylerin zihniyetlerinin her zaman dönüștürülebileceğini savunmaktadır (Beere, 2016).

Sabit ve gelişme zihniyetleri, bireyler için iki farklı psikolojik dünya oluşturmaktadır. Sabit zihniyette, öğrenciler her şeyden önce nasıl yargllanacaklarını önemserler: "Zeki" ya da "Zeki değil." Bu zihniyete sahip öğrenciler, genellikle hatalarını öğrenip düzeltme fırsatlarını reddederler. Hata veya eksiklikleri ortaya çıktığında düzeltmek yerine saklamaya çalışırlar. Ayrıca çaba sarfetmekten korkarlar çünkü çaba onları başarısız hissettirebilir. Onlara göre yeteneği olan bir insanın çabaya ihtiyacı olmamalıdır. Bu zihniyete sahip bireyler, yeteneğin tek başına başarı getirebileceğine inanırlar. Dweck (2007), bu düşüncenin gelişim ve başarı için en kötü inançlardan biri olduğunu ifade etmektedir.

Gelişme zihniyetinde olan öğrenciler öğrenmeyi önemserler. Gelişme zihniyeti öğrenme için güçlü bir tutku oluşturur. Öğrenciler bir hata yaptıklarında veya bir eksiklik sergilediklerinde onu düzeltmeye çalışırlar. Onlar için çaba olumlu bir davranıştır. Bu öğrenciler başarısızlık karşısında, yeni öğrenme stratejilerini ararlar (Dweck, 2007).

Sabit ve gelişme zihniyetinde olan öğrenciler arasındaki bazı düşünce farklılıkları aşağıda Tablo 1'de karşılaştırmalı olarak verilmiştir (Dweck, 2016).

Tablo 1.

Sabit ve Gelişme Zihniyeti Arasındaki Farklılıklar

\begin{tabular}{|l|l|}
\hline Sabit Zihniyet & Gelişme Zihniyeti \\
\hline Zekâ durağandır. & Zekâ geliştirilebilir. \\
\hline $\begin{array}{l}\text { Bir engelle karşılaştığında görevden } \\
\text { vazgeçebilir. }\end{array}$ & Engellere rağmen azmini sürdürür. \\
\hline $\begin{array}{l}\text { Çabayı çok fazla önemsemez. Zekâ ve } \\
\text { yeteneğe inanır. }\end{array}$ & Çabayı bir öğrenme fırsatı olarak görür. \\
\hline
\end{tabular}




\begin{tabular}{|l|l|}
\hline $\begin{array}{l}\text { Başkalarının başarısını kendisi için tehdit } \\
\text { olarak görür. Bu durumu onların daha zeki } \\
\text { olarak görülmesi şeklinde algılar. }\end{array}$ & $\begin{array}{l}\text { Başkalarının başarılarını kendisi için bir ilham } \\
\text { kaynağı olarak görerek öğrenme için dersler } \\
\text { çıkarır. }\end{array}$ \\
\hline $\begin{array}{l}\text { Yeteneklerin doğuştan geldiğine ve kolay } \\
\text { kolay değişmeyeceğine inanır. }\end{array}$ & $\begin{array}{l}\text { Yeteneklerin sabit olmadığına, çaba ve uygun } \\
\text { stratejilerle gelişeceğine inanır. }\end{array}$ \\
\hline $\begin{array}{l}\text { Mümkün olduğunca çok yetenekli } \\
\text { görünmeye çalışır. }\end{array}$ & $\begin{array}{l}\text { Mümkün olduğunca öğrenmeye ve kendini } \\
\text { iyileştirmeye çalışır. }\end{array}$ \\
\hline $\begin{array}{l}\text { Başarısız duruma düşmekten şiddetle } \\
\text { kaçınır. }\end{array}$ & Başarısızlığını bir öğrenme fırsatı olarak görür. \\
\hline $\begin{array}{l}\text { Diğer insanlarla etkileşimde; işbirliğini, } \\
\text { gelişmeyi ve dönütü engellemeye çalışır. }\end{array}$ & $\begin{array}{l}\text { Diğer insanları kendisiyle işbirliği yapmaya, dönüt } \\
\text { vererek eksik ve yanlışlarını bildirmeye ve } \\
\text { gelişmeye teşvik etmeye çalışır. }\end{array}$ \\
\hline
\end{tabular}

Gelişme zihniyetinde sebatın özel bir yeri vardır. Baruch-Feldman (2017), sebatı "uzun vadeli ve anlamlı hedefler için tutku ve dayanma gücü" şeklinde tanımlamaktadır. Yani sebat, yön ve bağlılık hakkında olup uzun vadeli hedeflere ulaşmaya odaklanmayı ifade etmektedir. Öğrencilerin sebat ve dayanıklılığını artırmak için bazı stratejilerin kullanılması gerektiğini vurgulayan Beere (2016) okullara bununla ilgili bazı öneriler sunmaktadır:

- Okul, öğrencileri esnek, kendine güvenen bir birey olmaya ve yeni şeyler denemeye teşvik etmelidir.

- Okul, en son eğitim araştırmalarını ebeveynlerle paylaşmalı, ebeveynleri çocuklarının öğrenimini en iyi şekilde nasıl destekleyebilecekleri konusundaki oturumlara katılmaya davet etmelidir.

- Okulda akademik başarıya ek olarak, tüm öğrenciler ve öğretmenler için değerli bir kişisel gelişim programı ortamı oluşturmalıdır.

- Okul, geri bildirim, çaba ve ilerlemeye odaklanmal,, öğrencilerin kendi kendilerine öğrenmeleri için adım atmalarına yardımcı olmalıdır.

- Okulda öğrenciler başarılarının yanı sıra çabaları için de ödüllendirilmelidirler.

Gelişme zihniyetinin, okul ortamlarında öğretilebileceği ve değişimin akademik başarıyı etkileyeceği birçok araştırmacı tarafından kabul edilmektedir. Okulda gelişme zihniyetinin öğretilmesinde öncelikle beyin ve onun işlenebilirliği hakkında bilimsel bilgileri farkettirmenin önemi üzerinde durulmalıdır. Beynin yeni ve zorlayıcı durumlarda daha güçlü ve daha verimli hale geleceği düşüncesi yaygınlaştırılmalıdır.

Gelişme zihniyetinde, üzerinde durulması gereken kavramlardan birisi de övgüdür. Kanouse, Gumpert ve Canavan-Gumpert (1981) övgüyü; "Belli ölçütlere göre, başka birinin ürünleri, performansları veya nitelikleri hakkında yaptığı olumlu değerlendirmeler" olarak tanımlamaktadırlar. Övgü güçlü bir motive edici araçtır. Öğretmenler öğrenci performansını arttırmak için övgüyü kullanabilirler. Ancak övgü çok dikkatli kullanılması gereken bir kavramdır. $\mathrm{Bu}$ açıdan övgü penisilin ilacının kullanımına benzetilmektedir. Penisilin ilacı hastaya uygulanacağı zaman; süre, doz ve alerjik reaksiyonlar konusunda gerekli önlemleri almak ne kadar önmeli ise; duygusal ilaç olan övgünün kullanımında da kurallara uymak o kadar önemlidir." (H.Ginott, 1965. Aktaran; Henderlong \& Lepper, 2002).

Ebeveyn ve öğretmenler çocukların zekâ ve yeteneklerini överek onlara kalıcı güven verdiklerini düşünebilirler. Ancak dikkat edilmediğinde bu iyi niyetli düşünce tam tersi bir etki de yapabilir. Aşırı ve kontrolsüz övgüye maruz kalan öğrenciler, zor durumlarla karşılaștıklarında zekâ ve 
yeteneklerinden şüphe duyabilirler. Bu nedenle öğretmen ve ebeveynler öğrencileri överken aşağıdaki noktalara dikkat etmeleri gerekmektedir (Dweck, 2007).

- Öğrencileri daha çok üstesinden geldikleri engellerden dolayı övün.

- Öğrencileri kullandıkları problem çözme stratejilerinden dolayı övün.

- Hatalara, eksiklere ve başarısızlıklara rağmen onların kararlılığını övün.

- Onları, zor görevleri seçmelerinden dolayı övün.

- Kendileri için oluşturdukları yüksek standartlar için övün.

- Kendilerine yapılan geribildirimler için olumlu tavırlarından dolayı övün.

- Bir konuda harcadıkları çaba miktarından dolayı övün.

Öğrencilerin kendi gelişimleri ile ilgili olumlu inançlara sahip olmaları, onların motivasyonlarını arttırarak öğrenme sürecinde daha yüksek başarılar elde etmelerini sağlayabilir. Zihinsel yeteneklerinin yanında çaba ve sebatın insan yaşamındaki önemini fark eden bireyler, öğrenme ve yaşam yolculuğunda her zaman bir adım önde olacaklardır.

\section{Gelişme Zihniyeti İle İlgili Yanlış Anlayış ve Uygulamalar}

Gelişme zihniyetine sahip olduğunu iddia eden birçok kişinin, bunun gerçekte ne olduğunu tam olarak anlamadığı ve gelişme zihniyetini öğretirken farklı uygulamaları kullandığı bilinmektedir. Bazı durumlarda ise gelişme zihniyeti kuramının tam tersi uygulamalara rastlanılmaktadır (Dweck ve Yeager, 2019).

Dweck (2016)‘e göre gelişme zihniyeti kuramı konusunda insanların sahip oldukları en önemli üç yanlış şunlardır:

1) İnsanlar gelişme zihniyetinde yetenek ve becerilerin çok önemli olmadığını düşünmektedirler. Oysa gelişme zihniyeti yetenek ve beceriyi reddetmez. Ancak bu özelliklerin geliştirilebileceğini söyler.

2) Bazılarına göre gelişme zihniyetini uygulamak çok kolaydır. Oysa gelişme zihniyetini uygulamak çok kolay değildir. Gelişme zihniyetini hem anlatmak hem de kendi yaşamında kullanmak için bireylerin çeşitli bilgi ve becerilere sahip olması gerekir.

3) Gelişme zihniyetinin çok basit bir kavram olduğu düşünülmektedir. Gelişme zihniyeti diğer kuramlarla ilişkili bir şekilde uygulanabilecek bir kuramdır. Çok basit bir kavram ya da uygulama değildir.

Birçok eğitimci gelişme zihniyetini sadece çabayla eşleştirerek öğrencinin çaba göstermesinin gelişme zihniyeti için yeterli olacağını düşünmektedir. Oysa gelişme zihniyetine sahip öğrencilerin çabaları yanında; kullandıkları stratejiler, yöntemler, teknikler, çevreden yardım istemeleri, değişik kaynaklardan ve kütüphanelerden yararlanma durumlarl, elde ettikleri sonuçlar, başkaları ile yaptıkları işbirlikleri, geziler, gözlemler, vb. boyutlar da dikkate alınmalıdır (Dweck, 2006).

Briceno (2015), gelişme zihniyeti ile ilgili olarak beş farklı karışıklığı dile getirmektedir: 1) Gelişme zihniyetinin tanımı ile ilgili karışıklık. İnsanlara gelişme zihniyetinin ne olduğu sorulduğunda, genellikle çok çalışmak, yüksek beklentilere sahip olmak, dirençli olmak veya açık ya da esnek olmak gibi birçok farklı yanıt alınır. Ancak gelişme zihniyeti tek başına bunların hiçbirini karşılamaz. Gelişme zihniyeti, niteliklerin değişebileceği ve zekâmızı ve yeteneklerimizi geliştirebileceğimiz inancıdır. 2) Gelişme zihniyetini geliştirmek için çocukları sadece çok çalıștıkları için övmek. Oysa onlara iyi bir rol model olmak gibi birçok başka yol da izlenebilir. 3) Gelişme zihniyeti yetişkinleri değil sadece gençleri değiştirmekle ilgilidir. Bu da yanlış bir düşüncedir. Gençleri eğitecek kişiler önce kendilerinden başlamalıdırlar. 4) Önemli olan tek şey 
zihinde olandır. Yanlış düşüncelerden birisi de başarının tek belirleyicisinin zihniyetimiz olmasıdır. Ama durum sadece böyle değildir. Bağlam, kültür, çevre ve sistemler de önemlidir. Öncelikle, insanların zihniyetleri çevrelerindeki insanlar tarafından güçlü bir şekilde şekillendirilir. 5) İyileştirme için tamamen inançları değiştirmenin yeterli görülmesi. İnançların değiştirilmesi, gelişme için önemlidir. Ancak bunların yanında öğrenme için öğretim yöntemleri, öğrenci merkezli yaklaşımlar, uygun etkinlikler ve müfredatın da iyileştirilmesi gerekir. Gelişme zihniyeti kuramından faydalanılması ve öğrenci motivasyonuna olumlu yönde etkisinin sağlanması için öncelikle doğru anlaşılması ve kuramın felsefesine yansıtan uygulanmaların yapılması gerekmektedir.

\section{SONUÇ VE ÖNERILLER}

İnsanların iki temel zihniyete sahip olduklarını vurgulayan zihniyet kuramı, bireylerin öğrenme motivasyonlarının bu inançlarıyla yakından ilişkili olduğunu varsaymaktadır. $\mathrm{Bu}$ temel zihniyetlerden birisi sabit zihniyettir. Sabit zihniyete sahip olan bireyler, doğuştan getirdikleri zekâ, yetenek ve kişilik gibi özelliklerinin değişmeyeceği düşüncesini taşımaktadırlar. $\mathrm{Bu}$ düşünceye sahip bireylerin doğal olarak öğrenme motivasyonlarının da düşük olacağı ileri sürülmektedir. Bunun aksine gelişme zihniyetine sahip olan bireyler; zekâ, yetenek ve kişilik gibi özelliklerin çaba ve azimle değişebileceği düşüncesini savunmaktadırlar. Bu düşünceye sahip bireylerin sürekli öğrenme ve kendini geliștirme konusunda daha yüksek bir motivasyona sahip olacakları vurgulanmaktadır.

Sabit ve gelişme zihniyetine sahip bireylerin başarı algıları da birbirlerinden farklıdır. Zekâyı sabit olarak algılayanlar sadece sonuca bakarlar. Sonuç iyi değilse her şey boşa gitmiştir. Gelişme zihniyetinde olan bireyler için çaba, sebat ve izlenilen öğrenme yolları sonuç kadar önemlidir.

Dweck, Walton ve Cohen (2014), akademik kararlılık ve başarı üzerinde durdukları bir çalışmalarında psikolojik faktörlerin, öğrencilerin akademik performansı için bilişsel faktörlerden daha önemli olabileceğini ifade etmektedirler. Bu psikolojik faktörler, öğrencilerin kendileri hakkındaki inançlarını ve okulla ilgili duygularını içerebilir. Uzun vadeli öğrenmeyi ve başarıyı teşvik eden bilişsel olmayan faktörler, akademik kararlılık başlığı altında bir araya getirilebilir. Akademik kararlılık; yoğun, akıllıca ve uzun süreli çalışma olarak tanımlanmaktadır. Bu açıdan öğrenme sürecini kontrol etmede önemli bir değere sahip olan öz düzenleme becerisi gibi yetkinliklerin başarıyı öngörme açısından IQ (Zekâ katsayısı) puanından daha önemli olduğu da ifade edilmektedir. Öğrenme sürecini düzenleyen öğrenciler öğrenmeyi etkileyen faktörleri kontrol ederek öğrenme için en uygun şartları da oluşturabilirler.

Gelişme zihniyetinde bireyin başarısı kadar başarı yolunda öğrendikleri de çok değerlidir. Bu durumu Carol Dweck (2006) Benjamin Barber'in; “Dünyayı zayıf ve güçlü olanlar ya da başarılı ve bașarısız olanlar diye bölmüyorum. Ben dünyayı öğrenenler ve öğrenmeyenler olarak bölüyorum." ş̧eklindeki sözüne atıf yaparak ön plana çıkarmaktadır. Bu kapsamda başarılı bir öğrenci için alınan yüksek notlar tek başına bir amaç değil gelişme ve gelişmenin bir yolu olarak görülmelidir.

Gelişme zihniyetinin öğrenme üzerindeki etkisini savunan Dweck (2006), insan beyninin çaba ile büyüyen bir kas olduğunu vurgulamaktadır. Bu nedenle beynin çalışma mekanizmalarının öğrencilere basitçe anlatılmasının önemi üzerinde durmaktadır. Ĕger öğrenciler beyinlerinin nasıl çalıştığı ve geliştiğini öğrenirlerse gelişme zihniyetini daha iyi anlayıp kendi yaşamlarına kolayca uygulayabilirler. 
Gelişme zihniyetinin öğretimi ve öğrenci başarılarına etkisi konusunda Amerika'da çok sayıda bilim insanının katılımı ile gerçekleşen ve dünyanın en saygın dergilerinden "Nature" de yayınlanan bir çalışmada (Yeager ve diğerleri, 2019), gelişme zihniyetinin öğretiminden sonra öğrenci başarılarının arttığı ve okul bırakma oranlarının azaldığı rapor edilmektedir. Gelişme zihniyetinin daha iyi anlaşılması ve öğrenme motivasyonuna katkı sağlaması için ebeveyn ve eğitimcilere bazı önerilerde bulunulabilir.

Öncelikle ebeveyn ve öğretmenlerin bu konuda iyi birer rol model olmaları gerekir. Öğrencilere yönelik söylemlerimiz önemlidir. Ancak söylemlerimize göre davranmıyorsak, söylemlerimizin etkisi oldukça azalacaktır. Öğrenciler daha çok davranış ve tutumları gözlemleyerek öğrenirler.

Ebeveynlerin ve öğretmenlerin, öğrencileri için yapacağı en iyi şeylerden birisi, onlara zorluklarla mücadele etmeyi ve hatalarından dersler çlkararak başarı için çaba ve sebatla devam etmeyi öğretmek olmalıdır.

Öğrencilerin zekâlarını sürekli övmek yerine, onların gösterdikleri çaba ve alışkanlıkları övmek; kendilerine daha fazla güvenmelerine sebep olacaktır. Ebeveynler ve öğretmenler övgülerini doğuştan geldiği düşünülen ve sabit olarak görülen zekâ ve yeteneğe değil, çabaya, izlenen yola ve kararlılığa yaparlarsa sabit zihniyetten gelişme zihniyetine geçişi kolaylaştırmış olacaklardır.

Ebeveynler ve öğretmenler öğrencilere; "Kazandın mı? Kaybettin mi?" gibi sorular sormak yerine, "Elinden gelen çabayı gösterdin mi? Sen daha iyi olabilirsin. Şimdilik başaramadın ama başaracaksın" demelidirler. Carol Dweck (2006)'in de çok önemsediği bir anlayıș olan, "henüz" kelimesinin gücünden faydalanılmalıdır. "Başaramadım" yerine "henüz değil, başaracağım" düşüncesinde olmak öğrenme motivasyonu için önemlidir.

Ebeveyn ve öğretmenlerin öğrenme konusunda çocukları motive etmeye çalışırken kullandıkları ifadeler de çok önemlidir. Çocuklarda gelişme zihniyetini geliştirmek isteyen ebeveyn ve öğretmenlere aşağıda sıralanan bazı örnek ifadeleri kullanmaları önerilebilir.

- "Sıkı çalıșmak başarıyı getirir."

- "Sıkı çalışarak zihinsel kapasiteni geliştirebilirsin.."

- "Herkes hata yapar."

- "Hatalarımızdan da öğrenebiliriz."

- "Çok çalışmanı önemsiyorum."

- "Bu konuda elinden geleni yaptığını söyleyebilirim."

- "Çaba, beynimiz için egzersizdir."

- "Bu çabayı gösterdiğin sürece birçok şeyi öğrenebilirsin."

Bu tür ifadeler öğrencileri gelişme zihniyetine daha kolay yönlendirebilir. Ancak söylemlerin etkili olması için ebeveyn ve öğretmenlerin bunları kendi tutum ve davranışlarında da göstermeleri gerekir.

Ebeveyn ve öğretmenler öğrencileri etiketlemekten kaçınmalıdırlar. Olumlu bir etiket olarak çok zekisin, çok akıllısın, ya da olumsuz bir etiket olarak matematikte çok iyi değilsin gibi ifadeler sabit zihniyet ifadeleridir. Bunlar öğrencileri motive etmek yerine kendilerini sınırlandırmalarına yol açabilir.

İnsanlar yaşama, farklı zekâ ve yetenekle gelebilirler. Ancak unutmamak gerekir ki bireylerin sahip oldukları düşünce, çaba ve deneyim, onları daha farklı yerlere götürebilir. Bu anlamda aile okul ve çevrenin insan üzerindeki olumlu etkileri, bireylerin hem düşüncelerini hem de başarılarını değiştirebilir. 


\section{KAYNAKLAR}

Arnold, J., Robertson, I. T., \& Cooper, C. L. (1991). Work Psychology: Understanding human behaviour in the workplace. Financial Times/Prentice Hall.

Au, J., Sheehan, E., Tsai, N., Duncan, G. J., Buschkuehl, M., \& Jaeggi, S. M. (2015). Improving fluid intelligence with training on working memory: a meta-analysis. Psychonomic bulletin \& review, 22(2), 366-377.

Baruch-Feldman, C. (2017). The Grit Guide for Teens: A Workbook to Help You Build Perseverance, Self-Control, and a Growth Mindset. New Harbinger Publications.

Bayrakçeken, S, Oktay, Ö, Samancı, O, Canpolat, N. (2021). Motivasyon Kuramları Çerçevesinde Öğrencilerin Öğrenme Motivasyonlarının Arttırılması: Bir Derleme Çalışması. Atatürk Üniversitesi Sosyal Bilimler Enstitüsü Dergisi, 25 (2) , 677-698.

Bedford, S. (2017). Growth mindset and motivation: A study into secondary school science learning. Research papers in education, 32(4), 424-443.

Beere, J. (2016). The Growth Mindset Edge: Your Guide to Developing Grit. Simon and Schuster.

Bernecker, K., \& Job, V. (2019). Mindset Theory. In Social Psychology in Action (pp. 179-191). Springer, Cham.

Briceno, E. (2015). Growth mindset: Clearing up some common confusions. KQED News; Mindshift.

Council, N. R. (2000). How people learn: brain, mind, experience and school. Washington, D. C.: National Academy Press.

Çelik, S.,\& Bayrakçeken, S. (2006). The effect of a 'Science, Technology and Society'course on prospective teachers' conceptions of the nature of science. Research in Science \& Technological Education, 24(2), 255-273.

Deckers, L. (2018). Motivation: Biological, psychological, and environmental. 5th Ed.,New York, NY, Routledge.

Dweck, C. S. (2007). The promise and perils of praise. Educational Leadership, 65(2), 34-39.

Dweck, C. S. (2016). Mindset: The new psychology of success (Updated edition).

Dweck, C.S, Walton, GM \& Cohen, GL (2014). Akademik kararlılık: Uzun vadeli öğrenmeyi destekleyen zihniyetler ve beceriler. Bill ve Melinda Gates Vakfı.

Dweck, C. S., \& Yeager, D. S. (2019). Mindsets: A view from two eras. Perspectives on Psychological Science, 14(3), 481-496.

Dweck, C.S. (2006). Aklını en doğru şekilde kullan (Çeviren: Uğurcan Kaya), İstanbul: Yakamoz Kitap.

Hastings, E. C., \& West, R. L. (2011). Goal orientation and self-efficacy in relation to memory in adulthood. Aging, Neuropsychology, and Cognition, 18(4), 471-493.

Henderlong, J., \& Lepper, M. R. (2002). The effects of praise on children's intrinsic motivation: A review and synthesis. Psychological bulletin, 128(5), 774. 
Jaeggi, S. M., Buschkuehl, M., Jonides, J., \& Perrig, W. J. (2008). Improving fluid intelligence with training on working memory. Proceedings of the National Academy of Sciences, 105(19), 6829-6833.

Kanouse, D. E., Gumpert, P., \& Canavan-Gumpert, D. (1981). The semantics of praise. New directions in attribution research, 3, 97-115.

Lin-Siegler, X., Dweck, C. S., \& Cohen, G. L. (2016). Instructional interventions that motivate classroom learning. Journal of Educational Psychology, 108(3), 295.

Mullins, L., \& Christy, G. (2011). Essentials of Organisational Behaviour. Harlow: Pearson Education Limited.

NASEM (National Academies of Sciences, Engineering, and Medicine). (2018). How people learn II: Learners, contexts, and cultures. National Academies Press.

Öztürk, E. Ö. (2012). Contemporary motivation theories in educational psychology and language learning: An overview. The International Journal of social sciences, 3(1), 33-46.

Pakdel, B. (2013). The historical context of motivation and analysis theories individual motivation. International Journal of Humanities and Social Science, 3(18), 240-247

Pintrich, P. R. (2003). A motivational science perspective on the role of student motivation in learning and teaching contexts. Journal of educational Psychology, 95(4), 667.

Schunk, D. H., Pintrich, P. R. \& Meece, JL (2014). Motivation in education: Theory, research, and applications. 4th Ed., Upper Saddle River,NJ; Pearson Education.

Şahin, S. (2007). Driving Key for Effective Learning: Motivation. Gaziantep University Journal of Social Sciences, 6(1), 1-8.

Yeager, D.S., Hanselman, P., Walton, G.M. et al. (2019). A national experiment reveals where a growth mindset improves achievement. Nature 573, 364-369. 